\title{
Correction to: The Use of Botulinum Toxin for Treatment of the Dystonias
}

\author{
Alfredo Berardelli and Antonella Conte
}

\section{Correction to: \\ Chapter "The Use of Botulinum Toxin for Treatment of the Dystonias" in: A. Berardelli and A. Conte, Handbook of Experimental Pharmacology, https://doi.org/10.1007/164_2019_339}

The chapter was inadvertently published without a more specific title according to SEO guidelines. A chapter title needs to be understandable when seen as a standalone item, e.g. on PubMed. The chapter title has now been corrected as 'The Use of Botulinum Toxin for Treatment of the Dystonias'.

The original article was corrected.

The updated online version of this chapter can be found at https://doi.org/10.1007/164_2019_339 